\title{
SABERES DOCENTES E A FORMAÇÃO DE PROFESSORES NA PERSPECTIVA DE UMA EDUCAÇÃO INCLUSIVA.
}

\author{
Teaching knowledge and teacher training in the perspective of inclusive education \\ Juliandersson Victoria Alexandre* \\ Liz Cristiane Dias ** \\ *Universidade Federal de Pelotas - juliandersonvictoria@gmail.com. \\ ** Universidade Federal de Pelotas - $\underline{\text { lizcdias@gmail.com. }}$.
}

Recebido em 06/08/2018. Aceito para publicação em 25/08/2018.

Versão online publicada em 20/11/2018 (http://seer.ufrgs.br/paraonde)

\begin{abstract}
Resumo: 0 seguinte artigo tem como propósito analisar o discurso contido no documento oficial do Ministério da Educação relativo a educação especial nos cursos de formação de professores, procurando auxiliar na construção dos saberes destes profissionais sobre o tema inclusão. 0 recorte de análise deste diz respeito à resolução no 2, de 1을 de julho de 2015, que define as Diretrizes Curriculares Nacionais para a formação inicial em nível superior, com suas propostas relativas à educação especial. Como resultado preliminar foi possível observar no texto político a evolução nas políticas públicas voltadas para a formação inicial de professores no que diz respeito a inclusão,todavia percebe-se nas universidades dificuldades na adequação de seus currículos de forma que se proponha aprofundamento do tema no decorrer dos cursos de licenciatura.
\end{abstract}

Palavras-chave: Educação Especial; Formação de Professores; Currículo.

Abstract: The purpose of this article is to analyze the articalations in official documents of the Ministry of Education related to special education in theacher training courses, seeking to assist in the construction of the knowledge of these professionals on the topic of inclusion. The analysis section of this article refers to Resolution No. 2 of July 1, 2015, which defines the National Curricular Guidelines for Initial Formation at the Higher Level, with its proposals for special education. As a preliminary result it was possible to observe evolution in the public policies aimed at the initial formation of teachers regarding inclusion, however it is perceived in the universities difficulties in the adequacy of their curricula in a way that proposes to deepen the subject during the undergraduate courses.

Key-words: Special Education; Teacher training; Curriculum.

\section{Introdução}

A grande diversidade de sujeitos com algum tipo de deficiência inseridos nas instituições educacionais e as políticas públicas voltadas para as ações de inclusão refletem diretamente nos saberes dos professores, sendo de vital importância a discussão dos currículos das licenciaturas nas universidades públicas, pois o professor em formação se encontra em formação permanente, necessitando que o currículo do seu curso contemple o estudo voltado as ações que proporcionem experiências sobre a temática da inclusão.

Atribuo a escolha do tema a minha condição de deficiente físico no ensino superior, no qual foi possível perceber em minha graduação, a lacuna presente no currículo referente as demandas voltadas a inclusão. Minha trajetória neste período foi de construção e entendimento de minhas necessidades físicas relativas ao espaço, ao se tratar do curso de Licenciatura em Geografia da Universidade Federal de Pelotas, mas além disso a falta de embasamento teórico e prático para os 
discentes sobre as demandas de educação inclusiva.

Vale salientar que o tema educação especial é um processo que precisa ser mais apurado para atender a demanda que está inserida nas instituições educacionais, ainda mais quando abordamos questões estruturais e psicológicas das pessoas com deficiência, cenário esse que para nós da Geografia relaciona-se diretamente a temas espaciais, mas ao mesmo tempo entendemos que é uma ação que necessita tempo para se concretizar, sendo primeiramente de extrema importância a materialização desta demanda em documentos oficiais e nos currículos das instituições.

A falta de um aprofundamento teórico e prático relativos a educação especial interferem diretamente na formação do professor e nos currículos das instituições formadoras, uma vez que o futuro profissional precisa ter experiências e leituras que sirvam como referencial para uma educação voltada a inclusão, que se proponha a oportunidade de desenvolvimento em igualdade de condições.

Para regulamentação destas experiências relativas a formação inicial do futuro professor o Ministério da Educação e o Conselho Nacional de Educação na sua resolução № 2, de 1ำ de Julho de 2015 define as Diretrizes Curriculares Nacionais para o Ensino Superior (cursos de licenciatura, cursos de formação pedagógica para graduados e cursos de segunda licenciatura) e para a formação continuada que será o recorte proposto deste estudo

A análise aqui proposta é parte da dissertação de mestrado que tem como objetivo analisar a experiência de alunos com deficiência física motora no ensino superior, com destaque à prática cotidiana nos ambientes acadêmicos de seus respectivos cursos, tendo como recorte a Universidade Federal de Pelotas/RS. Essa pesquisa também insere-se no escopo do Grupo de Pesquisa e Estudos: Espaços Sociais e Formação de Professores (GESFOP) no qual o autor é um dos integrantes.

Acredita-se que ao se inserir o debate sobre inclusão no currículo dos cursos de formação de professores, propicia-se ao futuro profissional da educação incorporar em seus saberes estas demandas, além do entendimento da diversidade de sujeitos que irá receber nas situações de ensinoaprendizagem no decorrer da docência, e nesse sentido, compreender as diferenças e individualidades de cada sujeito como potencialidades de conhecimento.

Tardif (2009) identifica que os saberes docentes são complexos e essenciais para a formação do professor, e que deles fazem parte além do percurso acadêmico as experiências de vida, sua trajetória pessoal e sua construção profissional. E que não é possível desconciliar desse percurso os sentidos do currículo expressos na macro e micro escalas dos processos educacionais.

É com esse objetivo que esse artigo se constrói, ou seja analisar os sentidos (passíveis de interpretação) de um texto político, neste caso as Diretrizes Curriculares Nacionais para a Formação Inicial em nível superior e suas propostas relativas à educação especial, no contexto das práticas dos cursos de formação de professores. Destaca-se que essa premissa parte da constatação de Ball (1992) ao afirmar que os significados e sentidos dos textos políticos não são fechados, mas sim passíveis de interpretações e contestação.

Busca-se investigar como se dá a apropriação dos textos oficiais e se os mesmos possibilitam a construção de propostas curriculares que propiciem uma prática formadora relativa a educação especial nos cursos de formação de professores, auxiliando este profissional na construção de seus saberes com base no movimento de respeito ás diferenças, produção de conhecimento e equacionamento de problemas no cotidiano, uma vez que no contexto educacional atual a diversidade social e cultural dos indivíduos encontra-se representada em todos os níveis educacionais, desde a educação infantil até o ensino superior e, de alguma maneira (nem sempre satisfatória) estão inseridas as pessoas com deficiência.

Como efeitos e resultados preliminares da análise, foi observada uma evolução nas políticas públicas voltadas para a formação inicial de professores, em especial no documento analisado, quando o mesmo se refere a educação especial, mas todavia, percebe-se nos cursos de formação uma grande dificuldade em adequar seus currículos nesta proposta de dar ênfase a educação especial, identificando um "vazio" neste aspecto, o que interfere diretamente na constituição destes saberes pelos futuros professores.

ParaOnde!?, Porto Alegre, v.10, n.2, p.63-69, 2018. Edição Especial com artigos publicados originalmente na XII ENANPEGE http://seer.ufrgs.br/paraonde 


\section{A formação de professores em uma perspectiva inclusiva.}

A discussão sobre a formação de professores surge em escala internacional nas décadas de 1980 e 1990, ganhando espaço no Brasil a partir da década de 2000. Entre alguns dos motivos que contribuíram para a sua emergência está o movimento de profissionalização do ensino e suas conseqüências para a questão do conhecimento dos professores na busca de um repertório de conhecimentos, visando a garantia e a legitimidade da profissão (Tardif, 2000).

Como forma de tencionar o tema surge um questionamento importante: Como os cursos de formação de professores estão direcionando suas atenções para propostas curriculares ligadas a educação inclusiva? Esta questão é de difícil resposta, pois as universidades federais com seus distintos contextos de cursos de formação de professores tratam de maneira diferente o tema inclusão, no caso da UFPel essa temática vem sendo discutida recentemente, e esse lapso temporal pode deixar lacunas na formação dos futuros docentes. Algo a se lamentar, pois o aumento significativo de alunos com alguma deficiência matriculados na educação básica e na educação superior teve um aumento significativo nos últimos anos.

Com relação aos dados da educação especial, o censo escolar registra uma evolução nas matrículas, de 337.326 em 1998 para 700.624 em 2006, expressando um crescimento de 107\%. No que se refere ao ingresso em classes comuns do ensino regular, verifica-se um crescimento de $640 \%$, passando de 43.923 alunos em 1998 para 325.316 em 2006, (Brasil. Inep. Censo Escolar 2006).

A quantidade de matrículas de pessoas com deficiência na educação superior aumentou 933,6\% entre 2000 e 2010. Estudantes com deficiência passaram de 2.173 no começo do período para 20.287 em 2010 - 6.884 na rede pública e 13.403 na particular.

O número de instituições de educação superior que atendem alunos com deficiência mais que duplicou no período, ao passar de 1.180 no fim do século passado para 2.378 em 2010. Destas, 1.948 contam com estrutura de acessibilidade para os estudantes. (BRASIL, 2012).

Todavia, sabemos que essa "política de números" apesar de ser um avanço, no que diz respeito à inclusão, está distante de ser ideal e adequada para aqueles que são inclusos.

Contudo, a inclusão escolar em particular aos alunos com deficiência físico-motora, vai além das modalidades de ensino e só terá êxito se houver adequações de espaço físico. A lei atual de diretrizes e bases da educação nacional lei n 9394/96, no artigo 59, preconiza que os sistemas de ensino devem assegurar aos alunos currículo, métodos, recursos e organizações específicas para atender as suas necessidades e sem dizer que muitas vezes as barreiras estão escondidas, oriundas de condições de acessibilidade, da organização escolar e do currículo (BRASIL1996).

Os números mostram o quanto é necessário o investimento na formação de professores nas universidades brasileiras e modificações curriculares que contemplem esta temática, proporcionando assim a construção destes saberes ao docente durante sua caminhada acadêmica, para que no futuro sua profissão tenha subsídios para perceber esta diversidade de sujeitos.

Atualmente temos como documento mediador nas questões relativas a essa questão a lei de inclusão das pessoas com deficiência que apesar de conter alguns vetos entrou em vigor em janeiro de 2016. Essa lei preconiza vários itens que devem ser tratados de forma institucional na legislação brasileira, propõe-se como base para investigação desse tema o capítulo IV referente ao direito a educação, na qual no seu Art.27 relata:

A educação constitui direito da pessoa com deficiência, assegurados um sistema educacional inclusivo em todos os níveis e o aprendizado ao longo de toda a vida, de forma a alcançar o máximo desenvolvimento possível de seus talentos e habilidades físicas, sensoriais, intelectuais e sociais, segundo suas características, interesses e necessidades de aprendizagem. (BRASIL, 2015).

0 capítulo que trata da educação é relatado até o artigo 30 da lei da inclusão, com várias resoluções no que diz respeito ao direito a acessibilidade em ambientes escolares públicos e privados, sistema educacional inclusivo em todos os níveis de ensino e implementação de conteúdos

ParaOnde!?, Porto Alegre, v.10, n.2, p.63-69, 2018. Edição Especial com artigos publicados originalmente na XII ENANPEGE http://seer.ufrgs.br/paraonde 
curriculares referentes a pessoa com deficiência em cursos de nível superior e de educação profissional técnica e tecnológica.

Tem-se como maior reivindicação neste contexto de inclusão no ensino superior o fato das políticas públicas que garantem aspectos como acesso, autonomia e segurança nos ambientes públicos para os indivíduos com alguma deficiência física, sensorial ou neurológica em especial os de licenciatura, tenham em seus planos pedagógicos ferramentas curriculares sobre o tema, consolidando uma base para formação dos futuros professores, que de subsídios para uma formação acadêmica humanizada e de acordo com a legislação, como orientado no seu artigo 28 - parágrafo XVI "A inclusão de conteúdos curriculares, nos cursos de nível superior e de educação profissional técnica e tecnológica, de temas relacionados à pessoa com deficiência nos respectivos campos de conhecimento".

As políticas públicas voltadas para a inclusão de pessoas com deficiência no Brasil é bem formulada, o que é criticado neste contexto é a sua não-efetivação nas instituições educacionais, isto reflete diretamente no compromisso de uma formação de professores que entendam a diversidade que existe e quais procedimentos mais adequados para cada situação.

Nesse sentido busca-se neste estudo dar visibilidade a re-contextualização dos saberes sobre a inclusão de pessoas com deficiência construídos nos currículos dos cursos de Licenciatura em detrimento das diretrizes propostas pelo Ministério da Educação para educação superior no que diz respeito a educação especial.

\section{Diretrizes curriculares nacionais para a formação inicial em nível superior: Apontamentos sobre a educação especial.}

A resolução no 2, de 1ำ de julho de 2015 que regulamenta e Define as Diretrizes Curriculares Nacionais para a formação inicial em nível superior (cursos de licenciatura, cursos de formação pedagógica para graduados e cursos de segunda licenciatura) e para a formação continuada foi homologada no dia 25 de junho de 2015 e considera que:

A consolidação das normas nacionais para a formação de profissionais do magistério para a educação básica é indispensável para o projeto nacional da educação brasileira, em seus níveis e suas modalidades da educação, tendo em vista a abrangência e a complexidade da educação de modo geral e, em especial, a educação escolar inscrita na sociedade. (MEC, 2015).

Esta resolução abrange, ou tenta abranger, a diversidade cultural e social presentes em todos os níveis educacionais, e no que diz respeito a formação do professor é necessário revisões nos currículos acadêmicos, no que diz respeito a estratégias que insiram os temas propostos, em especial o analisado neste artigo referente a educação especial. Para isto, a resolução n.2/2015 também enfatiza: "a importância do profissional do magistério e de sua valorização profissional, assegurada pela garantia de formação inicial e continuada, plano de carreira, salário e condições dignas de trabalho. Para dar início a esta mudança as Universidades precisam reestruturar seus currículos e Planos Pedagógicos, algo que a resolução também deixa claro é que:

As instituições de ensino superior devem conceber a formação inicial e continuada dos profissionais do magistério da educação básica na perspectiva do atendimento às políticas públicas de educação, às Diretrizes Curriculares Nacionais, ao padrão de qualidade e ao Sistema Nacional de Avaliação da Educação Superior (Sinaes), manifestando organicidade entre o seu Plano de Desenvolvimento Institucional (PDI), seu Projeto Pedagógico Institucional (PPI) e seu Projeto Pedagógico de Curso (PPC) como expressão de uma política articulada à educação básica, suas políticas e diretrizes. (MEC, 2015).

E também ressalta a diversidade cultural e social que deve ser proposta na formação do futuro professor, como podemos observar:

ParaOnde!?, Porto Alegre, v.10, n.2, p.63-69, 2018. Edição Especial com artigos publicados originalmente na XII ENANPEGE http://seer.ufrgs.br/paraonde 
As Diretrizes Curriculares Nacionais para a Formação Inicial e Continuada em Nível Superior de Profissionais do Magistério para a Educação Básica aplicam-se à formação de professores para o exercício da docência na educação infantil, no ensino fundamental, no ensino médio e nas respectivas modalidades de educação (Educação de Jovens e Adultos, Educação Especial, Educação Profissional e Tecnológica, Educação do Campo, Educação Escolar Indígena, Educação a Distância e Educação Escolar Quilombola), nas diferentes áreas do conhecimento e com integração entre elas, podendo abranger um campo específico e/ou interdisciplinar. (MEC, 2015).

A citação reflete o primeiro momento que as diretrizes destacam a educação especial em seu texto, em conjunto com demais temas sociais e culturais, como a educação para jovens e adultos e educação escolar indígena por exemplo.

No capítulo IV deste documento regulamentado pelo MEC fala da formação inicial para o magistério da educação básica em nível superior que compreendem os cursos de graduação de Licenciaturas, cursos de formação pedagógica para graduados, não licenciados e cursos.

A formação inicial destina-se àqueles que pretendem exercer o magistério da educação básica em suas etapas e modalidades de educação e em outras áreas nas quais sejam previstos conhecimentos pedagógicos, compreendendo a articulação entre estudos teóricopráticos, investigação e reflexão crítica, aproveitamento da formação e experiências anteriores em instituições de ensino.(MEC, 2015).

Em seguida no capítulo V: Estrutura e Currículo deste documento que trata da formação inicial do magistério da educação básica em nível superior a educação especial no ensino superior é referida em sentido amplo e disperso, sem um aprofundamento maior, referindo-se a Língua Brasileira de Sinais (Libras), que nos cursos de formação de professores passa de uma disciplina optativa para uma disciplina obrigatória nos cursos de Licenciatura.

Os cursos de formação deverão garantir nos currículos conteúdos específicos da respectiva área de conhecimento ou interdisciplinares, seus fundamentos e metodologias, bem como conteúdos relacionados aos fundamentos da educação, formação na área de políticas públicas e gestão da educação, seus fundamentos e metodologias, direitos humanos, diversidades étnico-racial, de gênero, sexual, religiosa, de faixa geracional, Língua Brasileira de Sinais (Libras), educação especial e direitos educacionais de adolescentes e jovens em cumprimento de medidas socioeducativas. (MEC, 2015).

No capítulo que trata da formação inicial para o magistério e orienta nas medidas para trabalhar com direitos humanos e sua diversidade aparece sempre a mesma citação, não demonstrando uma base sólida para a discussão, deixando esta tarefa a cargo livre das instituições, que por sua vez também não encontram (ou não querem encontrar) estratégias para inserir estas discussões em seus cursos de formação de professores.

Diante desse contexto, o avanço das pesquisas em políticas educacionais passa pela disposição dos pesquisadores em "[...] fazer perguntas diferentes e também procurar em lugares diferentes por respostas a essas perguntas" (BALL, 2014, p. 221). Talvez com isso seja possível observar o quanto limitado (temporal e espacialmente) tem sido o conhecimento que até agora produzimos acerca dos modos como os mercados têm influenciado o desenvolvimento das políticas educacionais de países como o Brasil.

E, mais do que isso, talvez nos seja possível construir novas habilidades de investigação para pensar-se os cenários da educação na atualidade.

\section{Considerações Finais}

É importante salientar que a formação de profissionais do magistério da educação básica tem se

Para0nde!?, Porto Alegre, v.10, n.2, p.63-69, 2018. Edição Especial com artigos publicados originalmente na XII ENANPEGE http://seer.ufrgs.br/paraonde 
constituído em campo de disputas de concepções, dinâmicas, políticas, currículos, entre outros. De maneira geral, a despeito das diferentes visões, os estudos e pesquisas, já mencionados, apontam para a necessidade de se repensar a formação desses profissionais. Nessa direção, considerando a legislação em vigor, com especial realce para o Plano Nacional de Educação.

Observando o contexto do documento que regulamenta as diretrizes curriculares nacionais para a formação inicial em nível superior podemos observar, mesmo que de forma vaga uma pequena evolução nas políticas propostas pelo Ministério da Educação, no que se refere a diversidade de sujeitos inseridos nas instituições de ensino e a preocupação com os cursos formadores de professores. Evolução essa que não deixa claro os significados e sentidos da proposta, sendo os mesmos passíveis de interpretações e contestação pelas instituições de ensino. (BALL eBOWE, 1992;COHEN, 1990).

Ao se deixar vago o contexto que se refere, nota-se que este processo de adaptação dos currículos nos cursos formadores ainda é lento e sem "fiscalização" do governo no que diz respeito a sua efetivação pelo menos em propostas de mudanças, tanto nos currículos como nos projetos pedagógicos dos cursos de graduação em licenciatura.

Como afirma Lopes (2011, p. 252) o currículo é uma luta política por sua própria significação e que a divulgação da obra é também uma forma de participar dessa luta, entende que "qualquer discurso é uma tentativa de dominar o campo da discursividade, fixar o fluxo das diferenças e construir um centro provisório e contingente de significação", a autora revela todo um contexto histórico e poder que influencia a construção dos currículos nas instituições de ensino, surgindo novos questionamentos:

Surgem na agenda dos estudos curriculares questões como: por que esse e não outros conhecimentos estão nos currículos, quem os define e a favor de quem são definidos; que culturas são legitimadas com essa presença e que outras são deslegitimadas por aí não estarem. (LOPES, 2011).

Visando assegurar a efetivação das diretrizes curriculares nacionais para a formação de profissionais da educação básica, para os cursos em andamento, define-se que os cursos de formação de professores que encontram-se em funcionamento deverão se adaptar à Resolução proposta no prazo de 2 (dois) anos (prorrogado recentemente por mais 1 ano, até 2018). Com relação a cursos novos, define-se que os pedidos de autorização para funcionamento de curso em andamento serão restituídos aos proponentes para que sejam feitas as adequações necessárias.

Cabe lembrar que a questão de formação de professores e sua construção de saberes para uma educação inclusiva diz respeito tanto para os profissionais da área de Geografia, como para as demais áreas do conhecimento, e o debate sobre políticas que regulamentam estas diretrizes para formação inicial é de extrema importância para o avanço nos currículos dos cursos de formação de professores em relação a diversidade social e cultural que se apresenta em nossa sociedade.

Em específico neste artigo, é sucinto afirmar que a educação especial para pessoas com deficiência esta se efetivando consideravelmente na rede básica de ensino e necessitam intervenções peculiares de acordo com suas necessidades, uma vez que a pessoa com deficiência tem o direito a autonomia e segurança nas instituições públicas, mas não apenas integradas em um ambiente sem contexto, mas sim incluídas em uma gama de estratégias que proporcionam este ambiente de respeito as diferenças, construindo sua identidade e socializando com as demais pessoas que não possuem tais necessidades.

\section{Referências}

BALL, Stephen J.; BOWE, Richard. Subjectdepartmentsandthe 'implementation' ofNational Curriculum policy: an overview oftheissues. Journalof Curriculum Studies, v. 24, no. 2, 1992.

BRASIL. Decreto no 3.956, de 08 de outubro de 2001. Promulga a ConvençãoInteramericana para a

ParaOnde!?, Porto Alegre, v.10, n.2, p.63-69, 2018. Edição Especial com artigos publicados originalmente na XII ENANPEGE http://seer.ufrgs.br/paraonde 
eliminação de todas as formas de discriminação contra aspessoas com deficiência. Diário Oficial da União, Brasília, DF, 9 set. 2001. p. 1.

BRASIL, lei no 13.146, de 6 de julho de 2015. Institui a Lei Brasileira de Inclusão da Pessoa com Deficiência (Estatuto da Pessoa com Deficiência). Diário Oficial [da República Federativa do Brasil], Brasília. Disponível em: < $\quad$ http://www.planalto.gov.br/ccivil 03/Ato20152018/2015/Lei/L13146.htm>.

. Conselho Nacional de Educação. Define as Diretrizes Curriculares Nacionais para a formação inicial em nível superior (cursos de licenciatura, cursos de formação pedagógica para graduados e cursos de segunda licenciatura) e para a formação continuada. Resolução CNE/CP n. 02/2015, de 1o de julho de 2015. Brasília, Diário Oficial [da] República Federativa do Brasil, seção 1, n. 124, p. 8-12, 02 de julho de $2015 . \quad$ Disponível em: http://pesquisa.in.gov.br/imprensa/jsp/visualiza/index.jsp?data=02/07/2015\&jornal=1\& pagina $=8 \&$ totalArquivos $=72$.

. Conselho Nacional de Educação. Dá nova redação ao Parecer CNE/CP 21/2001, que estabelece a duração e a carga horária dos cursos de Formação de Professores da Educação Básica, em nível superior, curso de licenciatura, de graduação plena. Parecer CNE/ CP no 28, de 2 de outubro de 2001. Brasília, Diário Oficial [da] República Federativa do Brasil, 18 de janeiro de 2002, Seção 1, p. 31.

CAVALCANTI, Lana de Souza. Geografia escolar na formação e prática docentes: o professor e seu conhecimento geográfico. In: SILVA, Aida Maria M. et. al. Educação formal e não formal, processos formativos e saberes pedagógicos: desafios para inclusão social. Encontro Nacional de Didática e Prática de Ensino. Recife: ENDIPE, 2006. p. 109 - 126.

COHEN, David K.; BALL, Deborah. Relationsbetweenpolicyandpractice: a commentary. EducationalEvaluationandPolicyAnalysis, v. 12, nํㅜ 3, 1990.

LACLAU, Ernesto. Emancipação e diferença. Rio de Janeiro: EdUERJ, 2011a.

LOPES, Alice Casemiro, \& Macedo, Elizabeth. Teorias do Currículo. São Paulo: Cortez, 2011.

HN Dias, M André - A INCORPORAÇÃO DOS SABERES DOCENTES NA FORMAÇÃO DE PROFESSORES. Revista Internacional de Formação de Professores. 2016.

MARTINS, Militz; ELISABETE, Rosa. CONSTRUÇÃO DOS SABERES DOCENTES DO PROFESSOR DE GEOGRAFIA Mercator - Revista de Geografia da UFC [enlinea] 2009, 8 (Sinmes) : [Fecha de consulta: 15 de março de 2017] Disponibleen: ISSN

Ministério da Educação / Secretaria de Articulação com os Sistemas de Ensino (MEC/SASE), 2014.

NÓVOA, A. Formação de professores e profissão docente. In: NóvOA, A. (Coord.). Os professores e sua formação. Lisboa: Dom Quixote, 1992. Disponível em http://repositorio. ul.pt/bitstream/10451/4758/1/FPPD_A_Novoa.pdf. Acesso em janeiro de 2016.

SOUZA, Vanilton Camilo de. O processo de construção do conhecimento geográfico na formação do professor de Geografia. Tese (Doutorado em Geografia), IESA/UFG,Goiânia, 2009.

TARDIF, Maurice. Saberes docentes e formação profissional. 16. ed. - Petrópolis, RJ: Vozes, 2014 